\title{
Exchanging Roles: \\ An Insight into the Theory of Value Co-Creation
}

\author{
Irene Raguenet Troccoli ${ }^{1, *}$, Nuno Álvares Felizardo Jr. ${ }^{2}$ \\ ${ }^{1}$ Universidade Estácio de Sá, Rio de Janeiro, Brazil \\ ${ }^{2}$ Universidade Federal de Viçosa, Minas Gerais, Brazil
}

\begin{abstract}
The service-centered view, more than considering consumers as focal parties, focuses on their individual and dynamic needs, besides stressing the collaboration and learning they can bring to the result of commercial transactions. It follows that the theory of value co-creating during the provision of services is based on the existence of players - or, rather, actors. They exist in a network structure rather than in a single-minded concern with restricted, pre-designated roles of producers, consumers and firms In a subversion of behaviors previously seen as normal or expected, under the theory of roles and scripts this qualitative-inductive exploratory-descriptive research using non-participant observation and quasi-ethnography suggests that co-production can occur and value can be phenomenologically co-created by means of the transposition of roles between the players who interact in a service experience. More than a service being the base of all exchange, the way of understanding what a service is, of understanding the benefit emerging from it, and of acting as a coproducer, can be reinterpreted by the players involved, to the point of subverting behaviors previously seen as normal or expected. Contribution to literature comes from deepening the explanations of the process of delivering a service both in terms of customer-provider interface and of the general experience of the client.
\end{abstract}

Keywords: service-dominant logic, co-production, value co-creation, physically disabled consumers, quasi-ethnography. 


\section{Introduction}

The service-dominant logic (SDL) proposed by Vargo \& Lusch (2004) state that the theory of value co-creating during the provision of services is based on the existence of players - or, rather, actors (Vargo \& Lusch, 2011). Without actor engagement, no resource integration happens and no value can be co-created (Storbacka et al., 2016). What generates value is the integration of resources that occur in an engagement platform when actors interact (Leclercq et al., 2016), and value materializes through, for example, co-ideation, co-valuation, co-design, co-testing and co-launching (Oertzen et al., 2018). Service marketing literature has stressed that the parties engaged in co-producing and in co-creating value - as logics say it should be - collaborate (Leclercq et al., 2016). Value can only emerge as there is interaction (Pirinen, 2016; Quero \& Ventura, 2015), which is clearly present in the $6^{\text {th }}$ foundational premise of the SDL (Vargo \& Lusch, 2006a) - the customer is always a cocreator of value - as well as is implied by the relational orientation specified in the $8^{\text {th }}$ foundational premise: a service-centered view is inherently customer oriented and relational.

One of the currents of this perspective to guide marketing theory and practice (Vargo \& Lusch, 2006b, 2008b; Lusch \& Vargo, 2008), that serves as a lens through which to view value creation, derived from the seminal work of Solomon et al. (1985), harking to the theory of roles, based on a theatrical metaphor, with external and internal clients participating in a meeting of services like on a stage. This is followed by the idea of generic actors that have ownership of, or access to, resources (Vargo et al., 2008), with the consequence that actors can have many different roles, as shown by Storbacka et al. (2016) and Brodie et al. (2016).

In furtherance of Solomon et al. (1985), who did not identify the different roles that the types of clients play in service setting, researchers who drew inspiration from them took care to fill this gap, such as Bowen (2016) and Larivière et al. (2017). However, these contributions have respected the original positions attributed to the service provider and its customer, with the former supplying the service and the latter receiving it, irrespective of more complex discussions developed from the concept of co-production (Vargo \& Lusch, 2004, 2008, A, 2016) - one of which coming from the $10^{\text {th }}$ foundational premise of the SDL (Lusch \& Vargo, 2006; Vargo \& Lusch, 2008, A): value is always uniquely and phenomenologically determined by the beneficiary.

Considering that value is co-created "for and by both parties throughout the time of their interaction" (Neghina et al., 2014, p. 1-2), it means that each actor plays his/her previously strict role - for instance, producer vs. consumer, or seller vs. buyer. But one may question whether these roles ought to be so strict. Could it be possible for value to be co-created in a dyadic relationship when one of these two actors momentarily gives up his/her role and is fully replaced by the other interacting actor present, actually exchanging roles albeit for a moment?

To date, academic research has not turned its eyes to this uncanny situation, probably because of the principle that value cannot be created without mutual actions of two actors; in other words, there would be no way for one actor to obtain value except through his/her direct interaction with the other actor. However, one can imagine that there are service-rendering situations in which one actor, being prevented from fully playing his/her role in the interaction, understands that there is a way to obtain value other than through direct action - for example, letting the other actor momentarily take on his/her role, in order to enable the service to be provided and the emergence of value (for both parts). This possibility finds shelter in the 10th foundational premise of the SDL, "Value is always uniquely and phenomenologically determined by the beneficiary" (Vargo \& Lusch, 2008, A, p. 7): if value depends on phenomenological perception by the beneficiary, this actor has the right to determine no matter how idiosyncratically - how he/she will perceive this value.

Being so, onde may ask under what special conditions of a service co-production and value cocreation, where the phenomenological perspective plays a relevant role, would it be possible for the 
functions of the actors involved in this meeting to be reinterpreted, to the point of subverting the respective behaviours? The answer to this question has meaningful potential to advance knowledge on the theory of value co-creation in the SDL upon deepening the contribution brought by phenomenology to this logic (see, for instance, Helkkula \& Kelleher, 2010, and Helkkula et al., 2012) in a way yet to be seen in literature, normally more interested in customer value propositions under managerial lens with respect to innovation and corporate ventures (Payne et al., 2017). This introduction is followed by a brief review on phenomenology applied to value co-creation; the method used; the most relevant evidence in light of co-production and value co-creation brought by our primary research; discussion and conclusion.

\section{Theoretical framework: phenomenology applied to value co-creation}

From an eminently phenomenological standpoint, value in experience is formed by "service customers' lived experiences of value that extend beyond the current context of service use to also include past and future experiences and service customers' broader lifeworld contexts" (Helkkula et al., 2012, p. 59). In other words, value in an experience is "directly or indirectly experienced by service customers within their phenomenological lifeworld contexts" (Helkkula et al., 2012, p. 61). Besides, Neghina et al. (2014, p. 2) have stressed the importance of focusing on the micro level of service interactions (Chandler \& Vargo, 2011), in order to provide answers regarding how customers and employees engage in value co-creation at the basic level of direct interactions, examining the different interdependencies between the interacting actors. As for actors' roles, it should be noted that, in SDL, no specific proposal exists for their changing. The nearest premise to this is found in the way of seeing resources as either operand or operant. But the bases of the theory show that the logic presented here, besides falling under its $10^{\text {th }}$ foundational premise, can also be related to two other premises, based on the logic that all participants are creating value together (Vargo \& Lusch, 2016 , p. 8): "Value is cocreated by multiple actors, always including the beneficiary" $\left(6^{\text {th }}\right.$ premise) and "actors cannot deliver value but can participate in the creation and offering of value propositions" ( $7^{\text {th }}$ premise).

This new way of viewing the possibility of value co-creation finds shelter in two theoretical propositions. The first involves the phenomenon of emotional contagion, referring to an emotional state triggered directly by perceiving the emotional state of another person, who is being observed (Preston \& Waal, 2002), configuring the phenomenon of emotional convergence. In this case, when front-line service providers demonstrate emotions, these can be transferred by contagion to the customers, and vice versa (Pugh, 2001; Rupp \& Spencer, 2006). Another theoretical proposal can be found in Zablah et al. (2017), who showed that customers and service providers who act in the front line, when taking part in repeated encounters, develop a tendency to react similarly to related events, leading them to experience the same emotions in response to the stimuli that occur during encounters.

Therefore, an addition to the premise that value is perceived and determined peculiarly by the customer in experiential and contextual form (Grönroos \& Voima, 2011) is constructively suggested in the present paper, related to the analysis of the creation of value of services by means of definition of value co-creation with focus on the roles of the customer and the company: that this process can involve exchange of roles. Indeed, in a later article Grönroos \& Voima (2013) seem to agree with this suggestion, when stating that the company can influence the experiences of its customers with regard to it, hence creating value, if it changes some temporal, spatial, physical or social aspects of the context of value creation.

We believe that this proposal finds shelter in the $10^{\text {th }}$ foundational premise of SDL - "Value is always uniquely and phenomenologically determined by the beneficiary" (Vargo \& Lusch, 2008, A), 
and refers to an extreme circumstance, with services whose enjoyment require skills that the client does not have. On such occasions, the service provider might be "invited" to perform an act that in reality belongs to the client's realm, but that he/she cannot practice. This situation would exist in the rendering of services where the customer's role requires an inexistent expertise, which would prevent him/her from enjoying the service and, consequently, from experiencing value. On this case, services would present themselves for the client as complex ones, given the client's inability to enjoy them. One can imagine such situations when the client is aware that he/she lacks physical or intellectual abilities to interact with the service provider, but even so wants the service rendering to be concluded since he/she phenomenologically feels that there is some value to be obtained. Such may be the case when the client has a physical handicap that prevents him/her from performing as a co-producer in a service rendering situation, as examined here.

\section{Method}

This qualitative-inductive exploratory-descriptive study that used non-participant observation (NPO) and quasi-ethnography (Elliot \& Jankel-Elliot, 2013) is intended to understand the behavior of physically disabled clients during their co-production of a leisure service, so it focused on acts, emotions and reactions of the participants, as well as gathered data to build concepts (Merriam \& Tisdell, 2015). The subjects are physically disabled clients using the service offered by the Praia para Todos ("Beach for Everyone") project (Instituto Novo Ser, 2020). Established on two beaches in the city of Rio de Janeiro, the project offers facilitated access to beach activities, at no charge, to people with various types of physical disabilities, such as a wheelchair pathway and amphibious chairs for ocean bathing. It relies on a staff of healthcare professionals and volunteers, to promote the participation of the physically-disabled clients in various beach leisure activities, of which ocean bathing is the focus of this study. For physically-disabled clients to access the beach and experience the activities offered, a series of physical adjustments are necessary, such as reserved parking spaces, ramps with handrails for access from the sidewalk to the beach and a wheelchair pathway on the sand, and floating chairs for bathing. These physical facilities are complemented by approximately 25 service providers, to allow the physically-disabled clients, with varying degrees of mobility, to allow experiential consumption of the beach activities, comprised of a paid technical team (physical education teachers, physiotherapists, occupational therapists) and interns responsible for developing the integration activities and assuring the safety of the physically-disabled clients and volunteers.

The NPO took place during six visits of one researcher to the project, allowing the observation of its physical aspects and of the attitudes and reactions of the physically-disabled clients when receiving the service and the team leading the activities. These observations were written down in a field journal at the end of each visit, allowing a follow-up of the changes that occurred during the study (Latour, 2005) and the subsequent analysis and interpretation, aided by still photos that were taken and videos of the interactions between the physically-disabled clients and service providers that were made. Apart from these observations, unstructured interviews with the physically-disabled clients, to better understand their anxieties, concerns and opinions about the project and to learn their state of mind about the service. Volunteers and paid staffers were also interviewed, in order to better understand how the project worked.

With regard to the results of the NPO, the events observed in the client-provider interaction were analyzed taking into consideration that one of the most relevant questions traditionally addressed by academics who study customer co-production refers to the initiatives that service providers should take to enable their clients to correctly engage in the activity and to achieve the expected result. In other words, upon beginning this research we followed the principle that, if the client is unable, or does not manage, to adequately engage in the activity, the experience desired by the provider will 
not be attained, causing dissatisfaction (Ford et al., 2012) - a principle that came to be imprecedently put to the test. One such line of research to address this issue, supported by studies on organizational behavior aimed at increasing human performance in companies, uses the goal-setting theory (Locke \& Latham, 1990, 2002): "(...) high (difficult) goals lead to a higher level of task performance than easy or vague and abstract goals, such as 'doing your best' " (Locke \& Latham, 2006, p. 265). However, other questions later arose regarding the cognitive capacity of individuals to attain those goals, leading to the theory of subconscious goals (Latham \& Locke, 2012). In turn, they used the concept of priming (Lashley, 1951), defined as the process of accidental activation of knowledge structures - for example, stereotypes - based on a determined situational context (Bargh, 2005). This focus on subconscious goal designation refers to a new and systematic technique for organizations, so that customers, once reminded of past successful behaviors, properly perform their roles as coproducers of a service. Having in mind that the more clues, or stimuli, of priming are given to the customer, the stronger will be their influence on the resulting answers, there is a typology about how this process can occur, based on the five human senses and subdivided into cognitive and emotional aspects (Ford, 2014). This tool, used together with personal values, helps identifying moments during which processes and methods stimulate customers to achieve their terminal values while enjoying beachside recreation activities through co-creation interactions. The content of the interviews was not submitted to any formal treatment, because of the mainly interpretative purpose of the research. It was taken in consideration that the study of customer co-production involves the initiatives that service providers should take to enable their clients to engage in the activity correctly and to achieve the expected result. After all, if the client is unable, or does not manage, to engage in the activity adequately, the experience desired by the provider will not be attained, causing dissatisfaction (Ford et al., 2012).

\section{Most relevant evidence in light of co-production and value co-creation brought by the primary research}

Starting with the ramp after the sidewalk at Barra da Tijuca Beach, the Praia para Todos project makes available a nylon "blue carpet" that leads to a complex of four yellow inflatable tents set up near the water - a section carefully chosen to guarantee only very small waves. This pathway allows wheelchairs to bypass the difficulties implied by sandy soil. During the field research, activities were supported by a team consisting of about 80 people. To engage in ocean bathing, physically-disabled clients use amphibious chairs, with wheels specifically designed for the sandy soil and that allow floating. The project team members take great care in handling the physically-disabled clients, especially when transferring them to and from the amphibious chairs.

What stood out most was the joyous and relaxed atmosphere, unlike one might imagine towards people with physical limitations, often very severe ones. Physically-disabled clients and service providers constantly interacted in a very positive mood, the latter always avidly willing to help. Before being taken to the water, blind people and amputees are offered to be carried without an amphibious chair for just a dip in the ocean, or to be transferred from their wheelchair to an amphibious chair. Some project members stated they had taken it upon themselves to improve the services as they gained more experience, striving to offer the physically-disabled clients the opportunity to enjoy that moment in spite of the restrictions imposed by their disabilities. In the case of amphibious chairs, four team members would grab it on its four corners and literally run to the water, with the speed being modulated by the age (the younger the faster, in general) and by the extent of their immobility (the more severe the disability, the greater caution is necessary). This running caused high excitement among physically-disabled clients and team members, especially when reaching the water, as it aimed at making the physically-disabled clients feel the wind and the 
sensation of running and jumping in the water, just like people without disabilities typically do. The team members stated they noted that this provided the physically-disabled clients with a sensation of running free and overcoming their limitations. Physically-disabled clients were allowed to remain in the ocean for as long as they wanted as long as there were not many other physically disabled clients waiting to be served, and it was observed that service providers strived to maximize the experience of ocean bathing. This was sought, for example, when team members strived to create a playful environment upon showing their pleasure when entering the ocean with a physically disabled client in the amphibious chair, splashing water on each other and sometimes on the physically disabled client, or making comments on sensations that many physically-disabled clients are unable to feel, such as water temperature. These actions aimed at creating a companionship atmosphere in the leisure activity, trying to make the physically-disabled clients enjoy as many sensations as possible, beyond a mere entry in the water. Building on Ford (2014), actions of the physically-disabled clients that could be identified as co-production of the service followed the concept of priming: when encountering a situational context of (co)existence that made them feel happy and free, these customers assumed "attitudes, actions and behaviors related to these stimuli" (Galvão et al., 2016, p. $19)$, prompting them to collaborate in the co-production. These situations referred to various sensory stimuli: 1) Sound: During ocean bathing activities, team members strived to stimulate the interaction of the physically-disabled clients and the water, referring to the pleasure of that moment ("Today the water temperature is perfect"); 2) Sight: When taking the physically-disabled clients in the amphibious chair for ocean bathing, the "race" carried out by the team provides visual stimulus, by the approximation to the water at a pace the physically-disabled clients are typically not used to feeling, reinforcing their sensation and experience; 3) Taste: At the extreme, physically-disabled clients who have never visited a beach are stimulated by the team members to taste the water with their tongues to sense its salinity; 4) Touch: The "race" in the amphibious chair to the sea aims at touch stimuli, allowing physically-disabled clients to feel the wind on the still sensitive parts of their bodies as though really running to enter the water.

Reactions of the physically-disabled clients to each of these stimuli were visible: 1) Sound: During ocean bathing, most of the verbalizations made by the team mixed encouragement with warning. For example, "a wave is coming" served not only as a warning of impending collision with the water (since the amphibious chair is introduced in the water in backwards position), but also to construct the experience of ocean bathing (to be immersed in salty water, "unable to avoid" this pleasurable contact); 2) Taste: The physically-disabled clients who had never been in the ocean and accepted the suggestion of the team members to taste the seawater at first showed a facial expression of displeasure, but then their semblance changed to one of relaxed curiosity; 3) Touch, together with sight: During the race to provide the wind sensation on the body, physically-disabled clients reacted favourably: some closed their eyes, some smiled, others shouted to go faster. When reaching the water, the reactions were to comment on the cool temperature, typically accompanied by smiles and requests to bathe without the support of the chair (keeping their heads above water only with the support of the team members) so they could be in total contact with the water.

When a physically disabled client for some reason could not be taken into the water as a part of the beach leisure experience, as a half-way solution the team members used their hands or buckets to wet the their bodies at the edge of the water. Another case of co-production - very common - was the cries of "faster, faster!" of the clients during the aforementioned "race" to the water in the amphibious chair, because observation and interviews indicated that this not only encouraged the project team members to participate in the experience, but also allowed them to fully understand the contribution of this performance to the experience of the physically disabled client when being taken to the ocean. Interestingly enough, not rarely a very unique reaction was noted on the part of the physically-disabled clients while in the water, which ignited the spark that pushed the main idea of 
this article: physically-disabled clients relied on the staff to "complement" their experience when their disabilities prevented them to. For instance, following a physically-disabled client asking the team members about the sensation of being underwater, or expressing their (impossible) desire to bodysurf, these team members performed these activities and verbalized their sensations to the physically-disabled client. This means that team members actually performed acts on physicallydisabled clients' behalf, as a way to allow these clients to imaginatively overcome their limitations and, through another person's act, feel as though they had lived it for real. In other words, one can say that roles were exchanged during a co-production experience, resulting in value co-creation for both parts: the client felt "as though" he/she had had the real experience, and the team member felt that this experience had been provided as much as it was possible.

\section{Discussion and conclusion}

In light of these co-production performances, it was possible to identify value co-creation between the parties during this service rendering. For example, the playfulness when physically-disabled clients are exposed to visual stimuli led to a cheerful and involving atmosphere that spread to team members. Gently wetting the physically disabled clients who are unable to perform this act by themselves shows that team members are more than mere basic service providers. Another example comes from the sense of touch, during the race to the sea in the amphibious chair. Upon closing their eyes to feel the wind on their faces seemed to give the physically-disabled clients - as mentioned $-\mathrm{a}$ feeling of running free of their limitations, as suggested by their smiles and outcries. Upon going beyond "technical" aspects of the service, team members invariably triggered reactions of joy that built an ambient of playful informality, which fed back positively to the happiness of the customers, evidencing the relevant role of the team members for value co-creation to be a two-way street (Grönroos \& Ravald, 2011). During the "race" of the amphibious chair to the sea, typical reactions of smiles and shouts of excitement conveyed the interaction of both parties. A similar moment of coproduction happened when team members offered to float clients in the water holding them without the support of the amphibious chair, leaving their bodies totally free to touch the sea. This act allowed the physically-disabled person to feel free of his/her limitations, without any apparatus needed for locomotion. But, as mentioned in the previous section of this paper, among all the evidence regarding co-production that fits in value co-creation theory, one aspect in particular brought a relevant insight to this theory from a new angle: role transposition between the players. It was observed that team members of the project "exchanged roles" with the customers, actually enjoying the service benefit in place and in favor of the customers. It was observed that ocean bathing of the physically disabled clients in Praia para Todos Project was transcended in functional terms: from a mere service that simply would "put the client into the salty water" it became an experimental event. What we observed, and perceived through the interviews, was that there was an extensive intangible benefit to the customer (Morais \& Santos, 2015), culminating in the extreme case of team members being asked to "feel for them" being underwater or bodysurfing. Team members who accompanied physically-disabled clients in the water engaged in practices - diving, bodysurfing - in lieu of the customer, in an effort to transfer actions that are impossible for physically disabled people, but are important to complete the repertoire of feelings of ocean bathing service. When encouraging the members to execute these actions, the physically disabled clients expressed their (impossible) desire and, upon acting for them, the team members attempted to transfer to these clients sensations that reduced their frustration. This suggests co-production in an eminently phenomenological event that managed to materialize co-created value. The roles transposition phenomenon finds support in the concept of value in experience of Helkkula et al. (2012), who believe that studies about value experiences in a specific lifeworld context do not 
provide discoveries that can be generalized by researchers and practitioners, but do capture experiences of subjective value in the social context. This facilitates a deeper understanding of how service customers make sense of their value experiences both lived and imaginary in specific social contexts. Value in an experience is "directly or indirectly experienced by service customers within their phenomenological lifeworld contexts" (Helkkula et al., 2012, p. 61). This led those authors to propose that an experience 1) can be both real and imaginary, and 2) is constructed based on previous, current and imaginary future experiences. The first proposition can be applied to this quasi-ethnographic study: within the phenomenological scope, the customers of the service can experience value as a result of indirect interactions with the phenomenon of the service (Meyer \& Schwager, 2007; Miller et al., 2009). Although not actually diving into the water or bodysurfing, physically-disabled clients imbibed the sensations of these actions, in a setting with strong phenomenological bias: the world is simply what it is to consciousness, i.e., a phenomenon (Husserl, 1990). The second proposition finds support in Pollio et al. (1997) when they say that experience is always intensely personal, and its meaning often changes according to one's reflection. This can be considered in the case of physically-disabled clients as people who have to deal with limitations and see life in a different way than that of the great majority of the population. As stated by Valle \& King (1978), knowing something about someone has both an external side - the observable physical or verbal behavior - and an internal, unobservable side, composed of emotions, thoughts and sensations. Given that experience is not observable, it makes sense that physically-disabled clients, afflicted by physical constraints peculiar to them, attach great value to the imaginary experience (Valberg, 1992), by "feeling" the experiences of others. Consistency of this insight to theory development can be found in Whetten (1989), who states that this is possible through the necessary exposure and understanding of elements that answer how and why this proposed contribution affects the accepted relations between the variables. Likewise, the present paper comes together within Whetten (1989), that important changes in the "how" of a theory are frequently stimulated by surprising results of a study, where the investigator's observations are inconsistent with the conventional wisdom. Roles transposition in service rendering opens a new chapter in the field of marketing studies in light of the theory of roles and scripts dating from the 1980s (see, e.g., Solomon et al., 1985; Biddle, 1986) and of the theory of roles expectations (Sarbin \& Allen, 1968) applied to service provision. In the case of theories of roles and scripts, although they have not reached the point of the transposition indicated here, they do consider the possible occurrence of subscripts, when the customer or the service provider faces what Schank \& Abelson (1977) defined as obstacles or errors - interferences that can occur in the scripts originally created as predictable. With respect to the theory of role expectations, a possible - but tenuous - point of tangency would be fact that behaviors expected by an agent are defined in relation to the other elements of the social structure (Merton, 1957). This phenomenon would result in the ability to predict the behavior of others - what role theory calls "playing the other's role" (Mead, 1935). This process of empathy, where an actor can anticipate the behavior of another, would lead the first to behave in line with the behavior predicted by the second (Rose, 1962). Finally, the theoretical insight proposed here is in line with what Grove et al. (2003) indicated many years ago as being one of the directions that service marketing research should take in the future, based on the opinions of experts of the area: a deepening of the explanations about the process of delivering service in terms both of the customerprovider interface and of the general experience of the customer. What is suggested here is that, more than a service being the base of all exchange as framed in the $1^{\text {st }}$ premise of Vargo \& Lusch (2016) regarding SDL, the way of understanding what a service is, of understanding the benefit emerging from it, and of acting as a co-producer, can be reinterpreted by the players involved, to the point of subverting behaviors previously seen as normal or expected. This insight to the theory can be questioned by the fact it is based on a study with a very specific group of customers, with limited 
physical capacity. This can be rebutted by the argument that it was possible to observe such a particular phenomenon precisely because of the uniqueness of this type of service customer, serving as a spark to broaden the comprehension of the theory. This echoes in Bamberger \& Pratt`s (2010) encouragement to research in unconventional contexts as a way to challenge the dominant singleloop learning. Besides this, it is worthwhile mentioning a convergence of the result obtained here with the thinking of Vargo \& Lusch (2008, A, p. 9), that SDL "could provide a basis for reorienting theories of society and economic science," enriching marketing with a broader vision than the focus restricted to normative principles based on corporate and economic interests. As any scientific study, this one has limitations. Perhaps the most relevant is the fact it is based on NPO method using a technique adapted to the field of business - quasi-ethnography. By relying on immersion in the field for less time than in traditional ethnography, this method obviously is less able to capture behavioral phenomena, restricting the richness of the conclusions, which is not fully offset by the triangulation by means of the interviews. This research is limited to presenting an unprecedented phenomenon that hopefully will contribute to further development of value co-creation theory and of SDL, a task for future studies that might model it and test it in different situations. Likewise, it would be interesting to extend the investigation to service settings where one might identify the transposition of papers with phenomenological inks, but without dealing with an extreme situation like physicallydisabled clients'. In closing, this article is an invitation to constructive academic debate.

\section{References}

Bamberger, P. \& Pratt, M. (2010) Moving forward by looking back: Reclaiming unconventional research contexts and samples in organizational scholarship. Academy of Management Journal, 53(4), pp. 665-671

Bargh, J. (2005) Bypassing the will: Toward mystifying the nonconscious control of social behavior. In R. R. Hassin, J. S. Uleman, \& J. A. Bargh (Eds.), The new unconscious, pp. 37-60. Oxford, UK: Oxford University

Biddle, B. (1986) Recent Developments in Role Theory. Annual Review of Sociology, 12, pp. 67-92 Bowen, D. (2016) The changing role of employees in service theory and practice: An interdisciplinary view. Human Resource Management Review, 26(1), pp. 4-13

Chandler, J. \& Vargo, S. L. (2011) Contextualization: network intersections, value-in-context, and the co-creation of markets. Marketing Theory, 11(1), pp. 35-49

Elliot, R. \& Jankel-Elliot, N. (2003) Using ethnography in strategic consumer research. Qualitative Market Research: An International Journal, 6(4), pp. 215- 223.

Ford, R. (2014) Prime time: the strategic use of subconscious priming to enhance customer satisfaction. Business Horizons, v. 57, v. 2, pp. 269-277, march-april.

Ford, R., Sturman, C. \& Heaton, C. (2012) Managing quality service in hospitality: How organizations achieve excellence in the guest experience. Clifton Park: Delmar

Galvão, F., Lucena, D. \& Prado, P. (2016) Um ensaio teórico sobre a teoria de priming no contexto de marcas esportivas. Revista Brasileira de Marketing (ReMark), 15(1), pp.16-27

Goulding, C. (2005) Grounded Theory, Ethnography and Phenomenology: A Comparative Analysis of Three Qualitative Strategies for Marketing Research. European Journal of Marketing, 39(3), pp. 294-308

Grove, S., Fisk, R. \& John, J. (2003) The future of services marketing: forecasts from ten services experts. Journal of Services Marketing, 17(2), pp. 107 - 121

Grönroos, C., \& Ravald, A. (2011). Service business logic: implications for value creation and marketing. Journal of Service Management, 22(1), pp. 5-22 
Grönroos, C. \& Voima, P. (2011) Making sense of value and value co-creation in service logic. Working Paper No. 559 [Online], available from: https://helda.helsinki.fi/ handle/10138/29218. Retrieved 12 January 2020

Grönroos, C. \& Voima, P. (2013) Critical service logic: making sense of value creation and cocreation. Journal of the Academy of Marketing Science, 41(2), pp. 133-150

Helkkula, A. \& Kelleher, C. (2010) Circularity of customer service experience and customer perceived value. Journal of Customer Behaviour, 9(1), pp. 37-53(17)

Helkkula, A., Kelleher, C. \& Pihlström, M. (2012) Characterizing Value as an Experience Implications for Service Researchers and Managers. Journal of Service Research, 15(1), pp. 59-75

Holbrook, M. \& Hirschman, E. (1982) The Experiential Aspects of Consumption: Consumer Fantasies, Feelings, and Fun. Journal of Consumer Research, 9(2), pp. 132-142

Husserl, E. (1990) A ideia da fenomenologia. Lisboa: Edições 70

Instituto Novo Ser. (2020). <http://www.novoser.org.br/projetos80.htm>. Retrieved 15 january 2020.

Larivière, B., Bowen, D., Andreassen, T., Kunz, W., Sirianni, N., Voss, C., Wünderlich, N. \& Keyser, A. (2017) "Service Encounter 2.0": An investigation into the roles of technology, employees and customers. Journal of Business Research, (79), pp. 238-246

Lashley, K. S. (1951) The problem of serial order in behavior. In L. A. Jeffress (Ed.), Cerebral mechanisms in behavior, pp. 112-136. New York: John Wiley

Latham, G. \& Locke, E. (2012) The effect of subconscious goals on organizational behavior. In G. P. Hodgkinson \& J. K. Ford (Eds.), International review of industrial and organizational psychology, 27, pp. 39-63. Hoboken, NJ: Wiley

Latour, B. (2005) Reassembling the Social: An Introduction to Actor-Network Theory. New York: Oxford Press University

Leclercq, T., Hammedi, W., Poncin, I. (2016) Dix ans de co-création de valeur : une revue integrative. Recherche et Applications en Marketing, 31(3), pp. 29-66

Locke, E. \& Latham, G. (1990) A Theory Of Goal Setting And Task Performance. Englewood Cliffs, NJ: Prentice-Hall

Locke, E. \& Latham, G. (2002) Building a practically useful theory of goal setting and task motivation: A 35-year odyssey. American Psychologist, 57(9), pp. 705-717

Locke, E. \& Latham, G. (2006) New Directions in Goal-Setting Theory. Current Directions in Psychological Science, 15(5), pp. 265-268

Lusch, R. F. \& Vargo, S. L. (2006). Service-dominant logic: Reactions, reflections and refinements.

Marketing Theory, 6(3), 281-288.

Lusch, R. \& Vargo, S. (2008). The service-dominant mindset. In: Service Science, Management and Engineering Education for the 21st Century. Bill Hefley and Wendy Murphy, eds. New York: Springer, pp. 89-96.

Mead, M. (1935) Sex and Temperament in Three Primitive Societies. New York: Apollo

Merriam, S. \& Tisdell, E. (2016) Qualitative research. A guide to design and implementation. San Francisco: Jossey-Bass.

Merton, R. (1957) The role set. British Journal of Sociology, n. 8, pp. 106-120

Meyer, C. \& Schwager, A. (2007) Understanding Customer Experience. Harvard Business Review, 85(2), pp. 116-126

Miller, K., Fabian, F. \& Lin, S. (2009) Strategies for Online Communities. Strategic Management Journal, 30(3), pp. 305-322

Morais, F. \& Santos, J. (2015) Refinando os conceitos de cocriação e coprodução: resultados de uma crítica da literatura. E\&G Economia e Gestão, 15(40), pp. 224-250 
Neghina, C., Caniëls, M., Bloemer, J. \& van Birgelen, M. (2014) Value cocreation in service interactions: Dimensions and antecedents. Marketing Theory, 15(2), pp. 221-242

Oertzen, A., Odekerken-Schröder, G., Brax, S. A. \& Mager, B. (2018) Co-Creating ServicesConceptual Clarification, Forms and Outcomes. Journal of Service Management, 29(4), pp. 641-679 Payne, A., Frow, P. \& Eggert, A. (2017) The customer value proposition: evolution, development, and application in marketing. Journal of the Academy of Market Science, DOI 10.1007/s117470170523-z

Pirinen, A. (2016) The barriers and enablers of co-design for services. International Journal of Design, 10(3), pp. 27-42

Pollio, H., Henley, T. \& Thompson, C. (1997) The Phenomenology of Everyday Life. Cambridge, UK: Cambridge University Press

Preston, S. \& Waal, F. (2002) The communication of emotions and the possibility of empathy in animals. In: Post, S.; Underwood, L., Schloss, J. \& Hurlburt, W. (Eds.). Altruistic love: Science, philosophy, and religion in dialogue, pp. 284-308. New York: Oxford University Press

Pugh, S. (2001) Service with a Smile: Emotional Contagion in the Service Encounter. Academy of Management Journal, 44(5), pp. 1018-1027

Quero, M.J. \& Ventura, R. (2015) The role of balanced centricity in the Spanish creative industries adopting a crowd-funding organizational model. Journal of Service Theory and Practice, 25(2), pp. 122-139

Rose, A. Human Behavior and Social Processes: An Interactionist Approach. Boston: Houghton Mifflin, 1962

Rupp, D. \& Spencer, S. (2006) When Customers Lash Out: The Effects of Customer Interactional Injustice on Emotional Labor and the Mediating Role of Discrete Emotions. Journal of Applied Psychology, 91(4), pp. 971-978

Sarbin, T. R., \& Allen, V. L. (1968). Role theory. In G. Lindzey \&E. Aronson (Eds.), The handbook of social psychology (2nd ed.), 1, pp. 488 -567. Cambridge, MA: Addison-Wesley

Schank, R. \& Abelson, R. (1977) Scripts, Plans, Goals and Understanding. New York: John Wiley and Sons, Inc.

Solomon, M., Surprenant, C., Czepiel, J. \& Gutman, E. (1985) A Role Theory Perspective on Dyadic Interactions: The Service Encounter. Journal of Marketing, 49(Winter), pp. 99-111

Storbacka, K., Brodie, R., Böhmann, T., Maglio, P. \& Nenonen, S. (2016) Actor engagement as a microfoundation for value co-creation. Journal of Business Research, 69(8), pp. 3008-3017

Valberg, J. (1992) The Puzzle of Experience, Oxford, UK: Clarendon Press

Valle, R. \& King, M. (1978) An introduction to existential phenomenological thought in psychology. In Valle, R. \& King, M. Existential phenomenological alternatives for psychology. New York: Oxford University Press

Vargo, S. L. \& Lusch, R. F. (2004) Evolving to a new dominant logic for marketing. Journal of Marketing, 68(January), pp. 1-17

Vargo, S. L., \& Lusch, R. F. (2006a). Service-dominant logic: What it is, what it is not, what it might be. In R. F. Lusch, \& S. L. Vargo (Eds.), The service-dominant logic of marketing: Dialog, debate, and directions, pp. 43-56. Armonk, NY: ME Sharpe.

Vargo, S., and Lusch, R. (2006b). The Service-dominant Logic of Marketing: Dialog, Debate, And Directions. London: Routledge

Vargo, S. L. \& Lusch, R. F. (2008a) Service-dominant logic: continuing the evolution. Journal of the Academy Marketing Science, 36, pp. 1-10

Vargo, S. L. \& Lusch, R. F. (2008b) Why service? Journal of the Academy Marketing Science, 36, pp. $25-38$ 
$3^{\text {rd }}$ International Conference on Applied Research in MANAGEMENT, ECONOMICS and ACCOUNTING

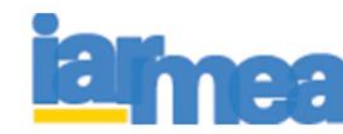

20 - 22 November, 2020

PARIS, FRANCE

Vargo, S. L. \& Lusch, R. F. (2011) It's all B2B and beyond...: toward a systems perspective of the market. Industrial Marketing Management, 40(2), pp. 181-187

Vargo, S. L. \& Lusch, R. F. (2016) Institutions and axioms: an extension and update of servicedominant logic. Journal of the Academy Marketing Science, 44, pp. 5-23

Vargo, S. L., Maglio, P. P., \& Akaka, M. A. (2008) On value and value co-creation: A service systems and service logic perspective. European Management Journal, 26(3), pp. 145-152.

Whetten, D. (1989) What constitutes a theoretical contribution? Academy of Management Review, 14(4), pp. 490-495

Zablah, A., Sirianni, N., Korschun, D., Gremler, D. \& Beatty, S. (2017) Emotional Convergence in Service Relationships: The Shared Frontline Experience of Customers and Employees. Journal of Service Research, 20(1), pp. 76-90 